\title{
Implementation Plan for the Irradiated Materials Characterization Laboratory (IMCL)
}

April 2013

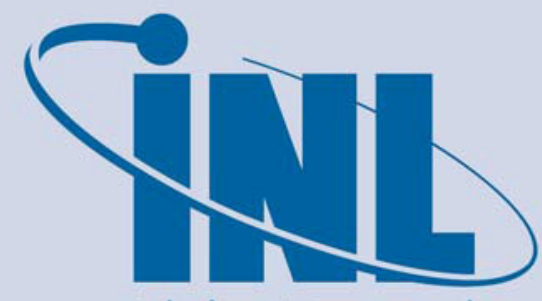

Idaho National Laboratory

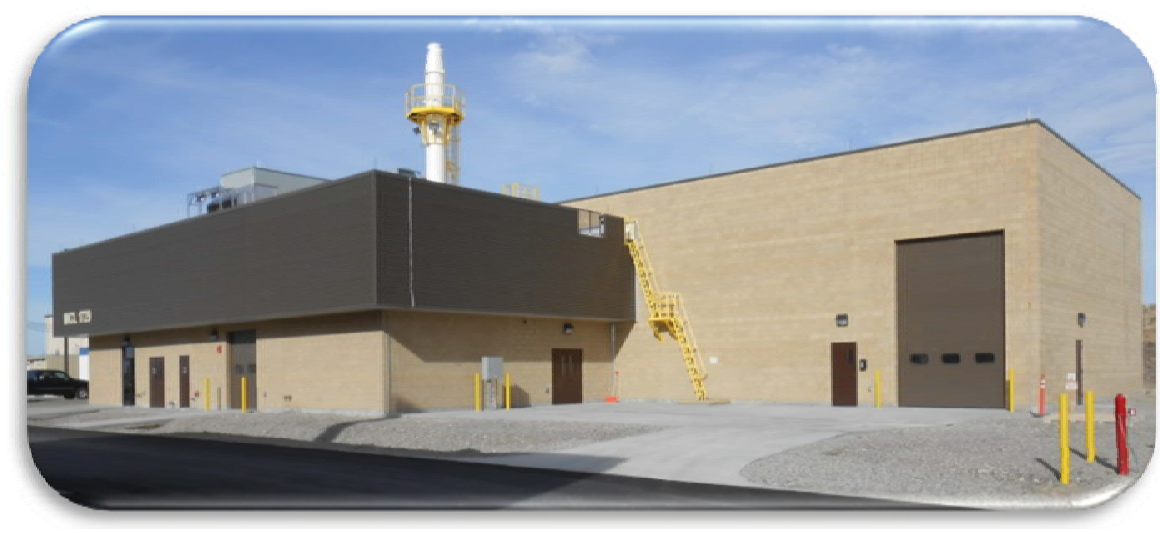

The INL is a U.S. Department of Energy National Laboratory operated by Battelle Energy Alliance 


\section{DISCLAIMER}

This information was prepared as an account of work sponsored by an agency of the U.S. Government. Neither the U.S. Government nor any agency thereof, nor any of their employees, makes any warranty, expressed or implied, or assumes any legal liability or responsibility for the accuracy, completeness, or usefulness, of any information, apparatus, product, or process disclosed, or represents that its use would not infringe privately owned rights. References herein to any specific commercial product, process, or service by trade name, trade mark, manufacturer, or otherwise, does not necessarily constitute or imply its endorsement, recommendation, or favoring by the U.S. Government or any agency thereof. The views and opinions of authors expressed herein do not necessarily state or reflect those of the U.S. Government or any agency thereof. 


\section{Implementation Plan for the Irradiated Materials Characterization Laboratory (IMCL)}

April 2013

Idaho National Laboratory Idaho Falls, Idaho 83415

http://www.inl.gov

Prepared for the

U.S. Department of Energy

Office of Nuclear Energy

Under DOE Idaho Operations Office

Contract DE-AC07-05ID14517 



\title{
Implementation Plan for the Irradiated Materials Characterization Laboratory (IMCL)
}

\author{
INL/EXT-13-29034 \\ Revision 0
}

April 30, 2013

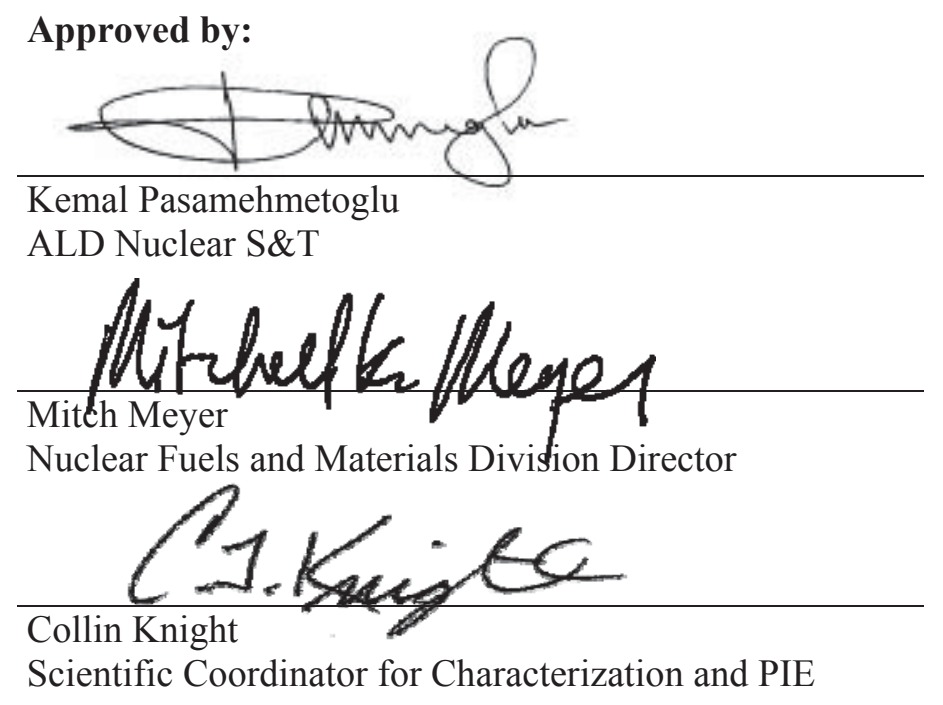

April 29, 2013

Date

April 29, 2013

Date

April 29, 2013

Date 
This page intentionally left blank. 


\section{CONTENTS}

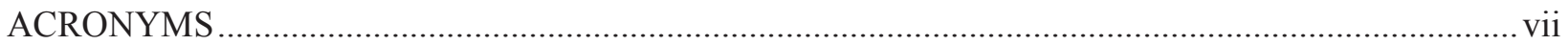

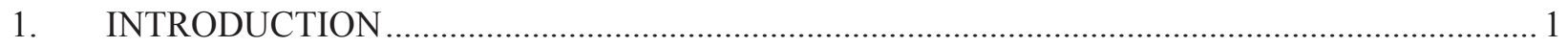

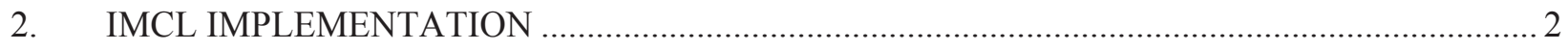

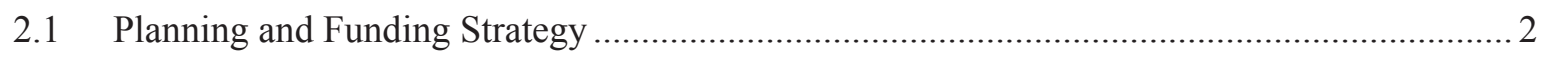

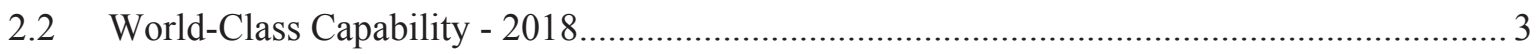

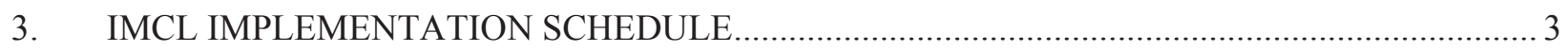

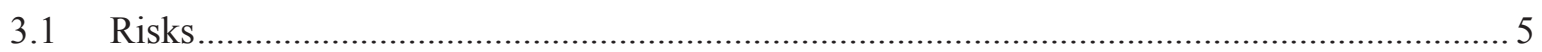

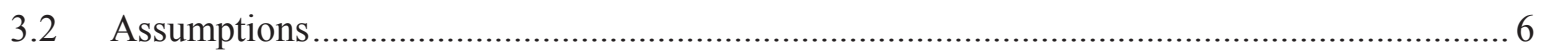

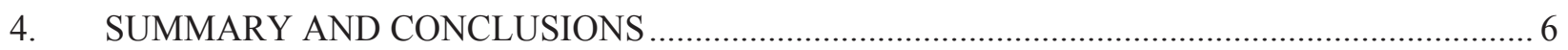

Appendix A Equipment Description and Background................................................................... 7

Appendix B IMCL Equipment - Long-Term Plans...................................................................... 9

\section{FIGURES}

Figure 1. IMCL Equipment Implementation Plan ... 4 
This page intentionally left blank. 


\section{ACRONYMS}

APIE

ATR

CAMs

CEP

DOE

DSA

EDM

EML

EPMA

FASB

FCRD

FIB

HFEF

IFM

IMCL

INL

LWR

MFC

MSA

MXRD

NSUF

ORR

PCMs

PEMP

PIE

RA

RAMs

RERTR

SEM

SSPA

TEM

VHTR
Advanced PIE Facility

Advanced Test Reactor

Constant Air Monitors

Capital Equipment Project

Department of Energy

Documented Safety Analysis

Electrical Discharge Machine

Electron Microscopy Laboratory

Electron Probe Micro-Analyzer

Fuels and Applied Science Building

Fuel Cycle Research and Development

Focused Ion Beam

Hot Fuel Examination Facility

Idaho Facilities Management

Irradiated Materials Characterization Laboratory

Idaho National Laboratory

Light Water Reactor

Materials and Fuels Complex

Management Self Assessment

Micro X-Ray Diffractometer

National Scientific User Facility

Operational Readiness Review

Personal Contamination Monitors

Performance Evaluation Measurement Plan

Postirradiation Examination

Readiness Assessment

Radiation Area Monitors

Reduced Enrichment Research and Test Reactors

Scanning Electron Microscope

Shielded Sample Preparation Area

Transmission Electron Microscope

Very High Temperature Reactor 
This page intentionally left blank. 


\section{Implementation Plan for the Irradiated Materials Characterization Laboratory (IMCL)}

\section{INTRODUCTION}

Over the last several years, Idaho National Laboratory (INL) has placed a major focus on a comprehensive approach to understanding fuels and materials behavior under irradiation. Laboratory facilities have been or are currently being upgraded. State-of-the-art equipment is being procured and temporarily installed in existing facilities awaiting the completion of the Irradiated Materials Characterization Laboratory (IMCL) and potentially, a second larger facility designed for Advanced Postirradiation Examination (APIE) and characterization of irradiated fuels and highly activated materials at greater throughput with a wider range of characterization tools. It is estimated that the IMCL could generate $\$ 23 \mathrm{M}$ of potential work in the next five years from DOE programs, industry, international collaborations, the Electric Power Research Initiative (EPRI), etc.

IMCL is a Hazard Category 2 nuclear facility that is flexible, reconfigurable, and supports a broad range of research on irradiated fuels and highly activated materials. The IMCL will provide research space that is suitable for much larger quantities of radioactive material than is possible today and is isolated from vibration, electromagnetic interference, and rapid temperature swings, as required by sensitive equipment/instruments needed to support programmatic needs.

The IMCL will also serve as a test bed for the application of advanced characterization techniques in a remote environment and for the networking of these advanced tools to outside users. Research capabilities demonstrated remotely in IMCL will be transferred to the proposed future facility (APIE) for advanced PIE capability.

Contractor construction of the IMCL was completed at the end of September 2012. The IMCL has been turned over to INL Operations, and training requirements are being finalized. The Documented Safety Analysis (DSA) is being reviewed by the Department of Energy (DOE), and a Management Self Assessment (MSA) is planned for August / September 2013 as the first step toward operational readiness. Several activities need to be completed to prepare for the MSA: installation of the stack monitor to fulfill the requirements of the facility air permit; installation of the Constant Air Monitors (CAMs), Radiation Area Monitors (RAMs), and Personal Contamination Monitors (PCMs); completion of the DSA review and approval process; and completion of the nuclear facility implementing documents.

This plan was developed to document and communicate INL's path forward for IMCL and as a response to the PEMP 3.1.1 deliverable for FY 2013. Please contact Lori Braase, Collin Knight, or Mitch Meyer for questions related to this plan or the PEMP deliverable. The updated PEMP language states:

IMCL will be used to prototype a number of instruments in a shielded environment with remote operations. When all the instruments are located in $I M C L$, this will provide new state-of-the art capability to examine irradiated nuclear fuels and materials with significant decrease in exposure and contamination to operators and technicians. 


\subsubsection{Demonstrate progress toward developing world-class post irradiation} examination (PIE) capabilities at the INL on a schedule which allows for effective prototyping of equipment in Irradiated Materials Characterization Laboratory (IMCL) and timely incorporation of results into design activities for the Advanced Post Irradiation Examination (APIE) project.

- Develop an IMCL Implementation Plan, by April 30, 2013, that addresses the installation of R\&D equipment in IMCL. Show progress towards the installation of equipment in IMCL in FY 2013, in accordance with the implementation plan. The implementation plan shall also include all work in FY 2014 and FY 2015 necessary to meet mission objectives.

\section{IMCL IMPLEMENTATION}

Upon completion of the proposed APIE Facility, likely after 2020, some equipment will be transitioned out of IMCL, which will then become a prototyping facility for APIE. IMCL will also be used as a mechanical testing facility. The pace at which IMCL can be populated with the desired instrumentation depends primarily on the yearly funding available between 2013 and 2018. Much of the instrumentation already exists at various locations at INL. In a few cases, new instrumentation will be procured or built for IMCL (as noted below) because of the logistical considerations and/or the need to use the existing instrument in its current location.

To experiment with and analyze highly radioactive fuel and material samples, instruments must be paired with gloveboxes located inside shielded cells with remote operation capabilities. The design, construction, procurement, and installation of the gloveboxes, shielded-cells, and manipulators are the primary cost and schedule drivers for operation of equipment in IMCL, not the cost of relocating the instruments. If the necessary funding were available today, IMCL could be fully populated and at full research operation mode by the end of FY 2015.

\subsection{Planning and Funding Strategy}

A major impact to implementation was the type and availability of funding that can be used to provide the shielding and confinement and to populate the facility with instrumentation.

As a result of the funding determination review, there will be no indirect funding available for capital equipment installation in IMCL for two years after facility startup in the first quarter of 2014. To accelerate the population of instruments in IMCL, the schedule will be managed with programmatic funding through 2015 (with limited indirect investment in FY 2015) and then with a combination of both programmatic and indirect funding in 2016 and beyond.

IMCL will become operational with existing equipment that will be relocated from the Materials and Fuels Complex (MFC) facilities to improve equipment access and sample analysis throughput. IMCL will be ready for the contractor Operational Readiness Review (ORR) in October 2013, with the follow-on DOE ORR in November 2013. IMCL will "startup" in FY 2014 as a Hazard Category 2 nuclear facility. New and relocated equipment/capabilities will be added as laboratory and program budgets permit. Separate readiness activities will be conducted for each new piece of equipment/capability as it comes on line. 
It is important to note that both the funding strategy and schedule are predicated on receiving required funding from the sources when needed as well as receiving ORR approvals. Any delays or funding reductions will significantly impact the ability to meet the 2018 objective.

\subsection{World-Class Capability - 2018}

With this implementation plan, the INL has positioned the IMCL for world-class PIE capability at the end of fiscal year 2018. The sample preparation and electron microscopy equipment will support material and fuel analysis at the nano scale. This includes the ability to support current and future INL missions, domestic and international industrial needs, and associated university educational programs. The core function of IMCL is to concentrate on new capabilities, specifically analysis of high dose rate samples using existing equipment, which will require the development of appropriate shielding and confinement systems (reducing the risk of radiation exposure). The lessons learned from the IMCL startup, operation, and equipment prototyping will be used throughout the design, construction, and startup of the APIE facility.

\section{IMCL IMPLEMENTATION SCHEDULE}

The IMCL Equipment Implementation Schedule in Figure 1 shows the progression of activities and cost estimates to equip IMCL for world-class capability by the end of FY 2018. Initial cost estimates are provided; however, there is no guarantee that the annual funding process will consistently support this 5-year plan. Schedules and work scope will be adjusted based on actual available funding. The current schedule supports the PIE needs for the following:

- Accident Tolerant Fuel program lead experiment irradiated in Advanced Test Reactor (ATR) (FY 2016)

- Used Fuel Disposition program (FY 2016)

- Long-term Transient Testing capability

- Federal programs, such as Reduced Enrichment Research and Test Reactors (RERTR), Fuel Cycle Research and Development (FCRD), Very High Temperature Reactor (VHTR), and National Scientific User Facility (NSUF).

At the end of FY 2013, the existing equipment to support facility startup will be installed and operational. Prerequisites for building startup include:

- Design and installation of building stack monitor (air permit)

- Purchase and installation of radiation/contamination measurement instruments

- Constant Air Monitors (CAMs)

- Radiation Area Monitors (RAMs)

- Personal Contamination Monitors (PCMs)

- Complete DSA process (DOE-ID review and approval and INL implementation)

- Complete nuclear facility implementing documents (criticality control, material balance, fire hazard analysis, etc.) 
- Conduct MSA

- Conduct Contractor RA/ORR (FY 2014)

- Conduct DOE ORR (FY 2014).

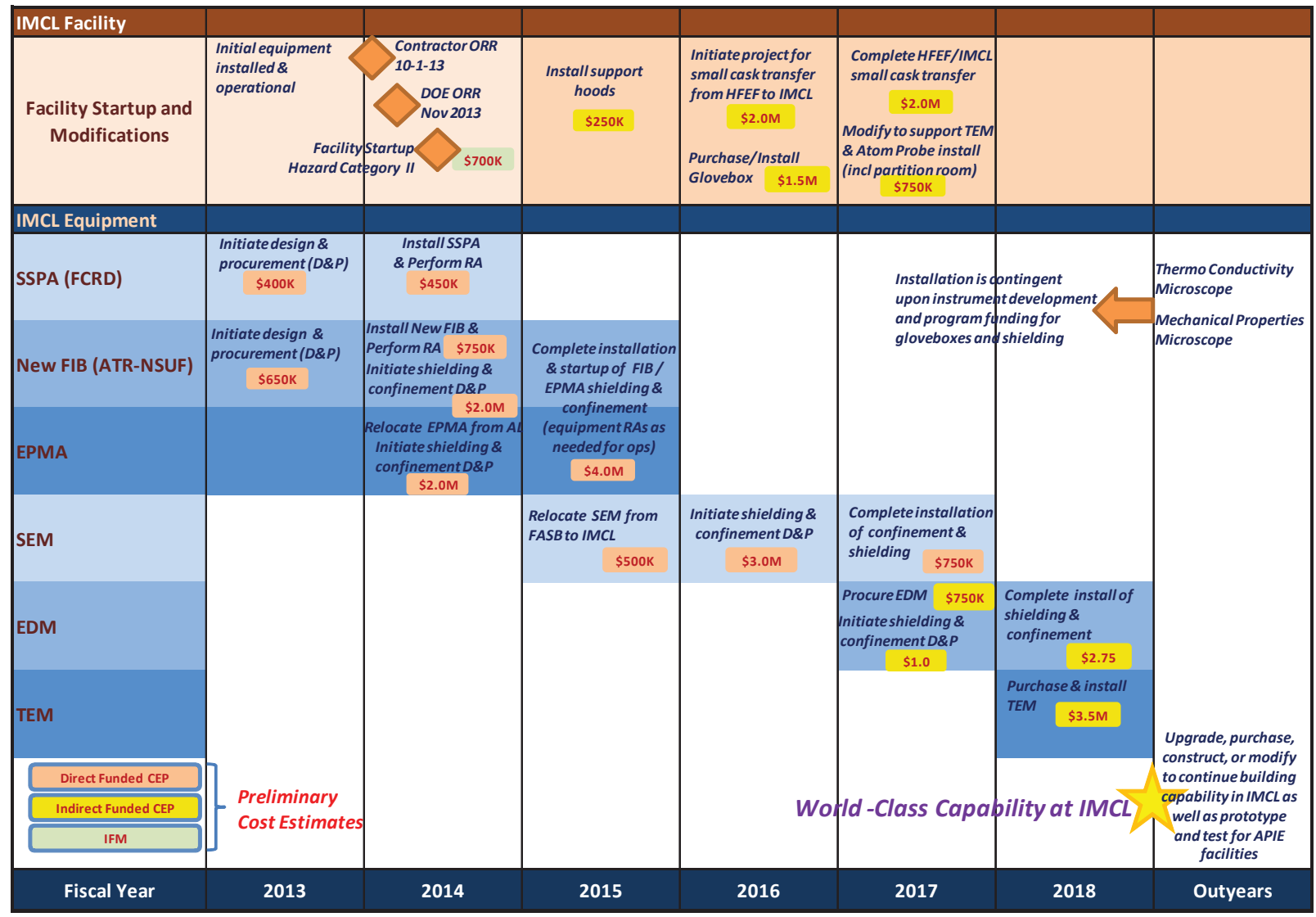

Figure 1. IMCL Equipment Implementation Plan

In addition, the design and procurement will be initiated for both the Shielded Sample Preparation Area (SSPA) and Focused Ion Beam (FIB), with an anticipated completion date in FY 2014, after facility startup. This equipment will provide higher sample preparation/analysis throughput.

In FY 2014, the IMCL will startup as a Hazard Category 2 facility, which will relieve pressure from other high-use facilities, including the Electron Microscopy Laboratory (EML) and the Fuels and Applied Science Building (FASB). The SSPA and new FIB will be installed, and the Electron Probe Micro-Analyzer (EPMA) will be relocated from the Analytical Laboratory to IMCL. The existing FIB will remain in EML to support low-dose sample preparation (it is not suited for remote operation). The design and procurement will be initiated for the FIB and EPMA associated shielding and confinement. All the activities for the SSPA, FIB, and EPMA will be direct-funded capital equipment projects (CEP).

The EPMA and FIB shielding and confinement will be completed in FY 2015 (fuel exam results should be available in FY 2016). This design will serve as a prototype for future IMCL 
instruments and potentially for the proposed APIE facility. Support hoods will be installed. Finally, a Scanning Electron Microscope (SEM) will be relocated from FASB to IMCL.

In FY 2016, the design and procurement will be initiated for the SEM shielding and confinement (direct-funded CEP). A glovebox will also be purchased and installed. A new project will be initiated to provide small cask transfer capability from the Hot Fuel Examination Facility (HFEF) to IMCL (both will be indirect-funded CEPs).

Installation of SEM shielding and confinement and the small cask transfer project will be completed in FY 2017. Facility modifications will be done to support Transmission Electron Microscope (TEM) and the Atom Probe installation. This includes the installation of a partition room. An Electrical Discharge Machine (EDM) will be procured along with the associated design and procurement of the shielding and confinement. (TEM and EDM will be indirectfunded CEPs.)

In FY 2018, the EDM shielding and confinement will be installed, and a TEM will be purchased and installed (indirect-funded CEP). At this point, the IMCL will be equipped and considered to be "World-Class."

After FY 2018, the Micro X-Ray Diffractometer (MXRD) power supply and x-ray source will be upgraded and the shielding and confinement installed. An Atom Probe will be purchased and installed to support programmatic demand. A new shielded enclosure sample preparation cell will be added to defuel Light Water Reactor (LWR) cladding for testing, enable sample storage, provide higher sample preparation throughput, and position IMCL as a mechanical testing lab with structural material machining capabilities.

The IMCL will remain a flexible and dynamic facility with prototyping capability for both equipment and associated shielding and confinement. New instruments and equipment will be added as programmatic funding and need arise. The IMCL will provide mechanical testing ability and will be fully integrated into the growing suite of characterization and PIE capabilities at INL.

Additional equipment information is included in the Appendices.

\subsection{Risks}

Implementation of the plan detailed above carries a number of risks that could affect funding availability and schedule. The risks to achieve world-class capability at IMCL include:

- The inability to obtain funding each year of the plan. Laboratory management is in discussions with DOE facilities and program personnel to obtain a commitment for the estimated funding within the proposed schedule.

- A delay in the execution and approval of the DOE ORR. Funding for IMCL ORR activities is not currently in the IFM budget for FY 2014. This issue is being discussed with IFM program management to place the activity on the funding gap list. If the ORR is delayed, it will delay IMCL implementation. 
- Schedule delays will result in loss of work that could be estimated as high as $\$ 23 \mathrm{M}$, over the next five years, from DOE programs, industry, international collaborations, the Electric Power Research Initiative (EPRI), etc.

\subsection{Assumptions}

The assumptions below are critical to the successful implementation of the plan by the end of FY 2018.

- The DOE ORR will be completed in November 2013.

- IMCL will start up in the first quarter of FY 2014.

- Funding for the next five years will be available to equip the IMCL.

\section{SUMMARY AND CONCLUSIONS}

This IMCL Implementation Plan provides a five-year strategy for world-class PIE capability. The strategy optimizes programmatic and indirect funding to make significant progress in design, procurement, and installation of instruments and support equipment. The plan also supports the design and construction of the APIE facility through lessons learned during IMCL implementation. This plan meets the April 30, 2013, PEMP 3.1.1 milestone.

As stated earlier, both the funding strategy and schedule are predicated on receiving required funding from the identified sources when needed as well as receiving ORR approvals. Any delays or funding reductions will significantly impact the ability to meet the 2018 objective. 


\section{Appendix A}

\section{Equipment Description and Background}




\section{Appendix A Equipment Description and Background}

\section{Installation of SSPA}

The Shielded Sample Preparation Area (SSPA) is a modular hot cell that was procured using direct funding by the RERTR program. The RERTR program decided not to complete installation and the equipment has been abandoned in place (in a covered condition) outside EML since 2011. INL management has decided to use the SSPA as a sample preparation cell in IMCL. However, because it was procured by direct funding, it is required that its installation be completed by direct funding also. At present less than half of the required funding is provided by the FCRD program. The completion of this activity is contingent upon availability of additional direct programmatic funding in the first half of FY 2014. If the funding becomes available on a timely basis, this activity will be completed by September 2014 .

\section{Installation of a New FIB}

A new Focused Ion Beam (FIB) instrument will be procured for installation in IMCL. Previous experience with the FIB that is currently in EML showed that, for IMCL applications it is more desirable to procure a less complicated (fewer analytic features) FIB with only the basic features required for sample preparation. A refurbished FIB has been identified and it is expected that it will be available in the last half of FY 2013 (but there is no guarantee on the exact date of the availability). The NSUF program is preparing a spend plan for the remainder of FY 2013 to verify it has sufficient funds to procure the instrument. Fiscal year 2013 plans only call for procurement of the instrument. Therefore, additional funding is required in FY 2014 to complete installation. Current plans call for completion of this activity by September 2014. The shielded cell around the FIB will be installed in FY 2015, pending funding availability.

\section{Installation of the EPMA}

The Electron Probe Micro-Analyzer (EPMA), along with the FIB, is targeted to be one of the first instruments which will be operational inside a shielded cell in IMCL. The current schedule shows the installation activities that will take place in FY 2014, with shielding and confinement provided in FY 2015. 


\section{Appendix B}

\section{IMCL Equipment - Long-Term Plans}




\section{Appendix B \\ IMCL Equipment - Long-Term Plans}

Based on today's priorities, a list was generated for the equipment/instruments that will be moved into IMCL. The list will be executed in the order listed below, but may be altered based on changes in programmatic needs or funding constraints. Installation of items 1-8 achieves World-Class status for the IMCL. The strategy also achieves the objective of prototyping equipment prior to completion of APIE.

1. Shielded Sample Preparation Area (SSPA) - Hot cell previously purchased by the RERTR program.

2. Focused Ion Beam (FIB) - New purchase to be used in IMCL inside a shielded cell. Existing FIB will remain in Electron Microscopy Laboratory (EML) and will continue to support low dose sample preparation.

3. Electron Probe Micro-Analyzer (EPMA) - Move from MFC Analytical Laboratory (AL) into a shielded cell.

4. Scanning Electron Microscope (SEM) - Move the FEG-SEM from FASB to IMCL, to be operated in a shielded cell.

5. Install EDM in a shielded enclosure.

6. HFEF design for small closed cask transfer to IMCL to reduce dose and increase productivity.

7. Purchase and install glovebox/hood for facility support.

8. Transmission Electron Microscope (TEM) - Purchase a new TEM for use in IMCL. TEM samples are small enough that the instrument does not need to be shielded.

9. Shielded enclosure sample preparation cell. SSPA will remain functional. Benefits of shielded enclosure are to: (a) defuel LWR cladding for testing, (b) enable sample storage in IMCL, (c) increase sample preparation throughput, and (d) machine structural materials to start transitioning the IMCL towards a mechanical testing laboratory.

10. Micro-X Ray Diffractometer (MXRD) -Upgrade and move from AL to IMCL, to be operated in a shielded cell.

11. Atom Probe - Purchase and install in IMCL to support increasing programmatic demand and prototype its use with highly radioactive materials.

The total estimated cost of this plan is on the order of $\$ 40 \mathrm{M}$ (preliminary estimate - not validated) and some of the items require more than a year to complete, depending heavily on timely funding availability and multi-year funding planning. 